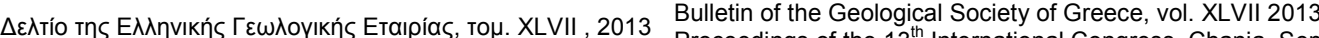
Proceedings of the $13^{\text {th }}$ International Congress, Chania, Sept.

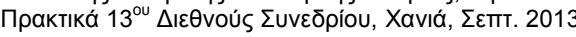
2013

\title{
LANDSLIDE DETECTION USING ALOS OPTICAL AND RADAR DATA. A CASE STUDY FROM THE ILIA PERFECTURE
}

\author{
Nikolakopoulos G. K. ${ }^{1}$, Choussiafis $\mathrm{Ch}^{2}{ }^{2}$ and Karathanassi V. ${ }^{2}$ \\ ${ }^{1}$ University of Patras, Department of Geology, Sector of Applied Geology and Geophysics, \\ knikolakop@upatras.gr, \\ ${ }^{2}$ National Technical University of Athens, School of Rural and Surveying Engineering, \\ christos_hous@hotmail.com, karathan@survey.ntua.gr,
}

\begin{abstract}
In this study the usefulness of the ALOS optical and radar data for landslide monitoring is examined. ALOS contains three sensors, commonly referred to as the "three eyes" of ALOS. These sensors are: the Panchromatic Remote-Sensing Instrument for Stereo Mapping (PRISM), the Advanced Visible and Near Infrared Radiometer type 2 (AVNIR-2), and the Phased Array type L-band Synthetic Aperture Radar (PALSAR). The area of study is located in a small village named Sykies near to the city of Andritsena in Western Peloponnese. The area suffered during the last years from enormous fires. As a result many landslides have been recorded. One of the latest Landslides has been recorded on January 2009 as a consequence of heavy rains. That landslide was mapped in situ using differential GPS. The possibility of detecting and mapping the specific landslide using ALOS data is examined in this study and the results are presented. Thirty ALOS radar images within a period of three years, two ALOS Prism data sets and two ALOS AVNIR collected over the same area within a year were used.

Key words: Interferometry, photogrammetry, landslide.
\end{abstract}

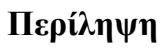

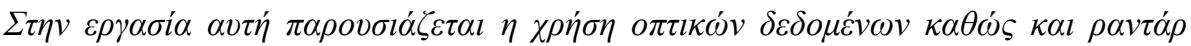

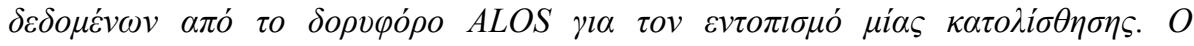

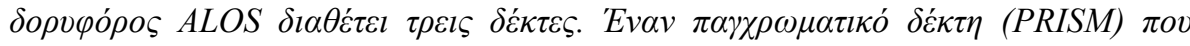

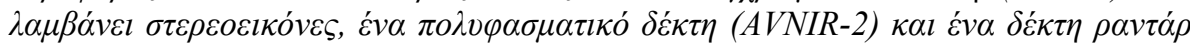

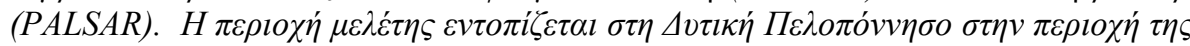

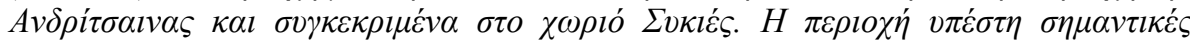

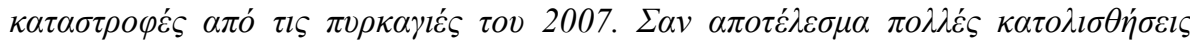

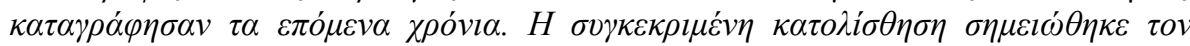

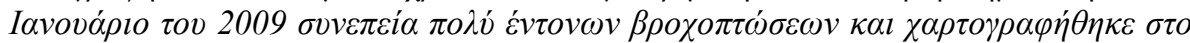

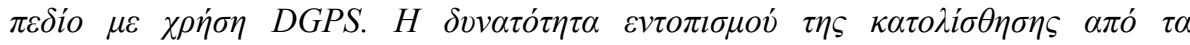

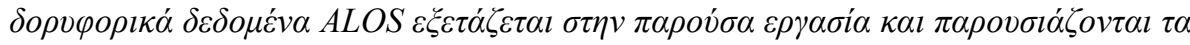

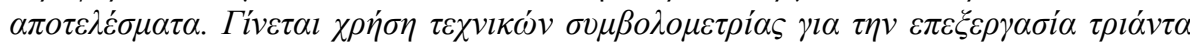

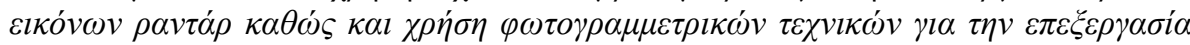

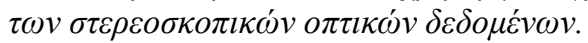

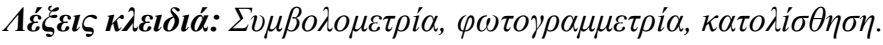

XLVII. No 3 - 1489 


\section{Introduction}

The term landslide includes a wide range of ground movement types, such as slides, falls, flows etc. mainly based on gravity with the aid of many conditioning and triggering factors. Especially in the last two decades, there is an increasing international interest on the landslide susceptibility, hazard or risk assessments.

Rockslide activity endangers surface and subsurface infrastructure, and is able to trigger other hazards, by, for instance, damming a river and causing a flood hazard. Digital image analysis techniques for mapping landslides and monitoring related elevation changes from repeated DEMs are comparably often applied (Mantovani et al, 1996; Mass et al., 1997; Weber and Herrmann, 2000; Chandler, 2001; Nikolakopoulos et al., 2005). Some other studies focused mainly on the use of remote sensing data on horizontal displacement measurements (Powers et al., 1996; Baum et al., 1998; Kaab, 2000).

In this paper a combined use of Remote Sensing, GIS and GPS data for landslide mapping is presented. The possibility of detecting and mapping the specific landslide using ALOS PALSAR radar data and interferometric techniques, ALOS PRISM stereo data and photogrammetric techniques and ALOS VNIR data is examined and the results are presented. Thirty ALOS radar images within a period of three years, two ALOS Prism data sets and two ALOS AVNIR collected over the same area within a year were used. The orthorectified ALOS optical data, the DSM produced by the stereo images, and the GPS measurements were implemented in ARCGIS in order to make the necessary measurements and create the final maps.

\section{Study Area}

The area of study is located in a small village named Sykies near to the city of Andritsena in Western Peloponnese. The area is characterized by large seismicity and the Landslides phenomena are very often. The area is covered by geological formations of the Pindos zone. The base of the Pindos zone is a clastic formation overlaid by resistant limestones of Upper Triassic to Liasian age. Alternations of radiolarites (Dogerian-Malmian age), consisting of mudstones and ribbonbedded cherts and Lower Cretaceous limestones are next in the sequence (Jacobshagen et al., 1978). An Upper Cretaceous clastic formation (known in the literature as 1st flysch), including mudstones, cherts, terrigenous turbidites and pelagic limestones, with layers of chert is next in the sequence (Piper and Pe-Piper, 1980). The Eocene flysch rocks complete the sequence (Papanikolaou, 1986).

The area also suffered during the last years from enormous fires. As a result many landslides have been recorded. One of the latest Landslides has been recorded on January 2009 as a consequence of heavy rains.

\section{Landslide Mapping}

A few days after the landslide took place, in situ mapping was done using a Mobile Mapper GPS receiver with an external antenna and EGNOS correction (Figure 1).

The produced map of the landslide is presented in Figure 2. The Landslide has affected a small road in the village and a garden. The head of the landslide is just in front of two olive trees (Figures 3 and 4) about two meters from the house basement. The head of the landslide is about 27 meters long. At the south edge of the landslide a small river is present. The head and the foot of the landslide are mapped with the GPS (Figure 1). In Figure 2 the black dashed line represents the head of the landslide while the red one represents the foot of the landslide. The road network is presented with black color line. A part of the road has collapsed (Figure 4).

$\underline{\text { XLVII, No } 3-1490}$ 


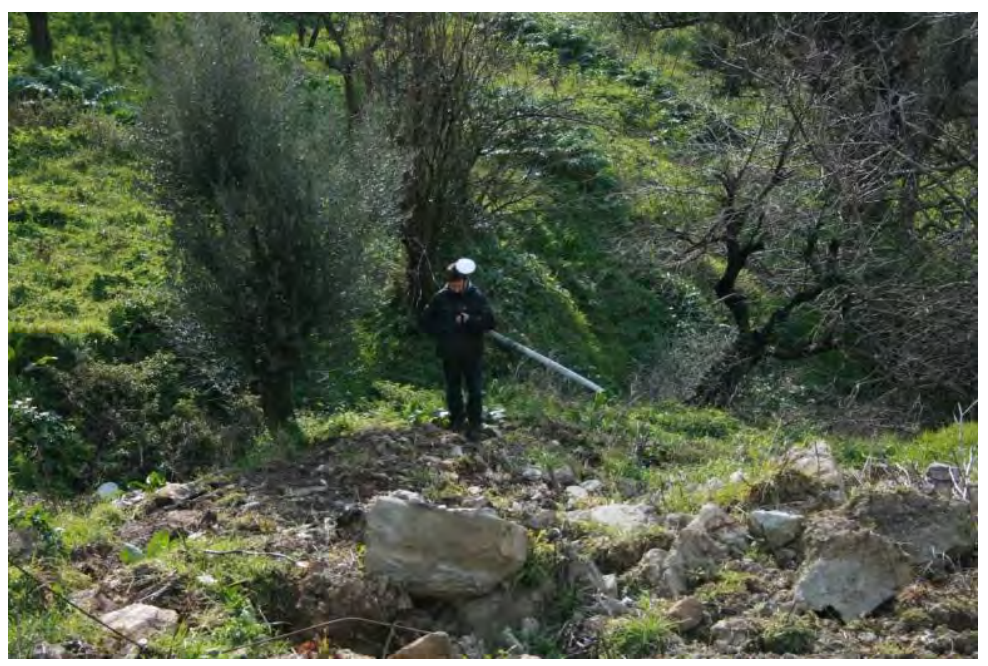

Figure 1 - The in situ mapping of the landslide using a Mobile Mapper GPS receiver with an external antenna.

\section{ALOS Radar Data Processing}

\subsection{Method Description}

Standard two pass Differential SAR Interferometry (DInSAR) was performed to detect the general ground deformation on the study area and specifically to identify and get information on the activity of the known landslide on Sykies. According to this technique the topographic phase contribution is removed from an interferogram in which interferometric phase surface displacement is recorded (Massonet et al., 1993). According to a general model, interferometric phase can be written as:

$$
\varphi=\varphi_{\text {flat }}+\varphi_{\text {topo }}+\varphi_{\text {defo }}+\varphi_{\text {atm }}+\varphi_{\text {noise }}
$$

where $\varphi$ is the interferometric phase obtained from two SAR acquisitions, $\varphi_{\text {flat }}$ is the flat earth phase, $\varphi_{\text {topo }}$ is the topographic phase, $\varphi_{\text {defo }}$ is the deformation phase, $\varphi_{\text {atm }}$ is the atmospheric delay phase and $\varphi_{\text {noise }}$ is the noise. In order to detect the ground deformation by unwrapping the phase $\varphi$, it is necessary to eliminate all the components of equation (1) apart from $\varphi_{\text {defo }}$ component. The flat earth component can be removed by using the orbit information correction, as well as an external DEM to generate the topographic phase which is then subtracted from the interferogram (Zhou et al., 2005; Yu and Ge, 2010). The topographic phase cancellation performed by the generation and subtraction of the so-called synthetic or simulated interferogram. Within this study, the used external DEM which used for the elimination of $\varphi_{\text {flat }}$ and $\varphi_{\text {topo }}$ components, was a DEM provided by KTIMATOLOGIO S.A.. This DEM has a $5 \mathrm{~m}$ pixel size, and its average accuracy was estimated to be $4.08 \mathrm{~m}$ according to GCPs evaluation for confidence level $95 \%$. The specific DEM is the most accurate official DSM covering the Greek territory. As far as the atmospheric component concerns, it mainly depends on the water vapor content of the atmosphere and is considered as an error in non atmospheric applications. Finally, the noise component refers to thermal noise and the contribution of changes of individual scatterers. The noise component is removed by applying filtering techniques (adaptive filters e.g. Goldstein) on the interferogram and/or SAR images. So, by removing or ignoring the components that do not contribute to height information, (1) can be written as following:

$$
\varphi \cong \varphi_{\text {defo }}(2)
$$



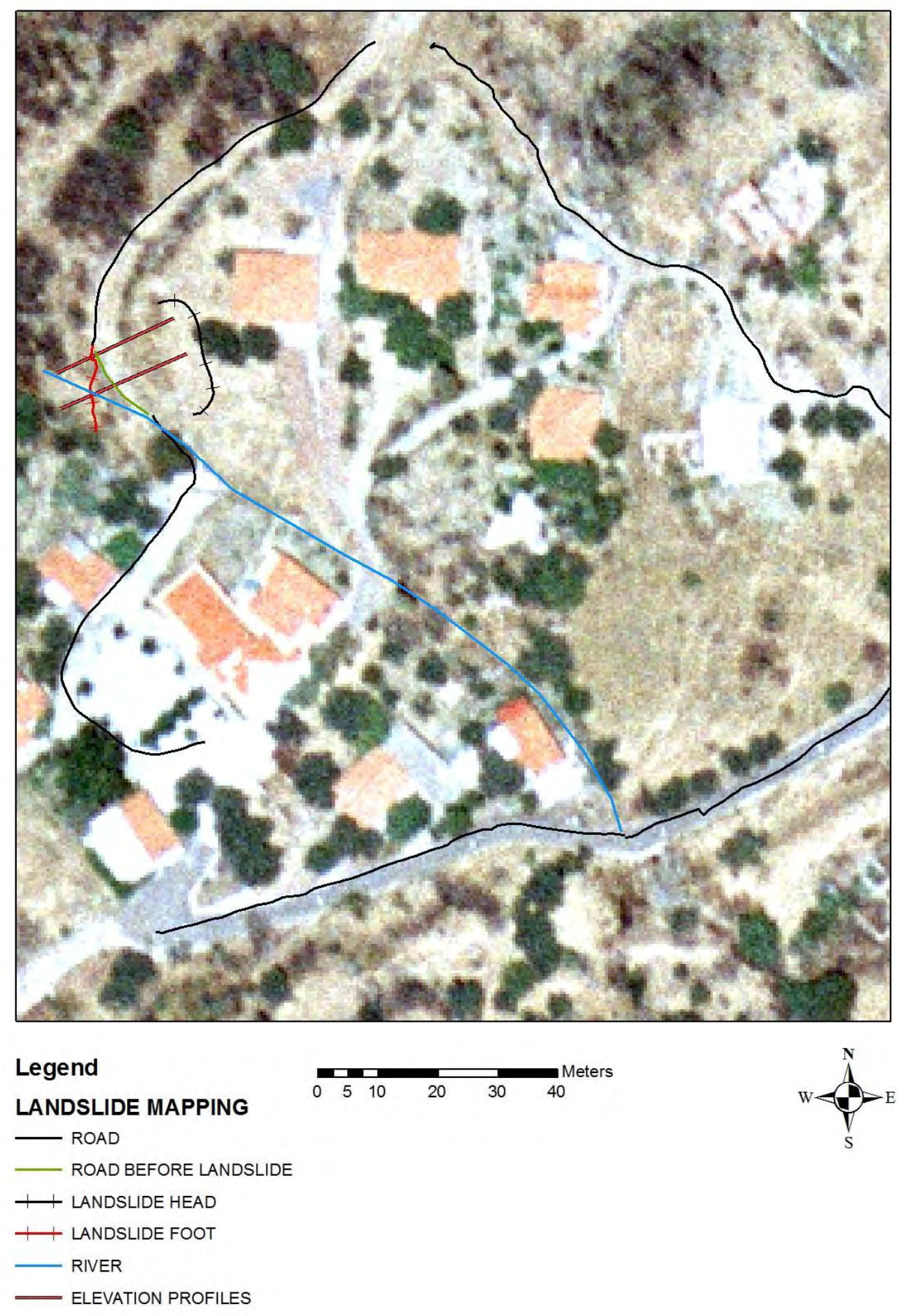

Figure 2 - The map of the landslide. The head of the landslide is in front of two olive trees. The black dashed line represents the head of the landslide while the red one represents the foot of the landslide. The road network is presented with black color line. A part of the road has collapsed. 


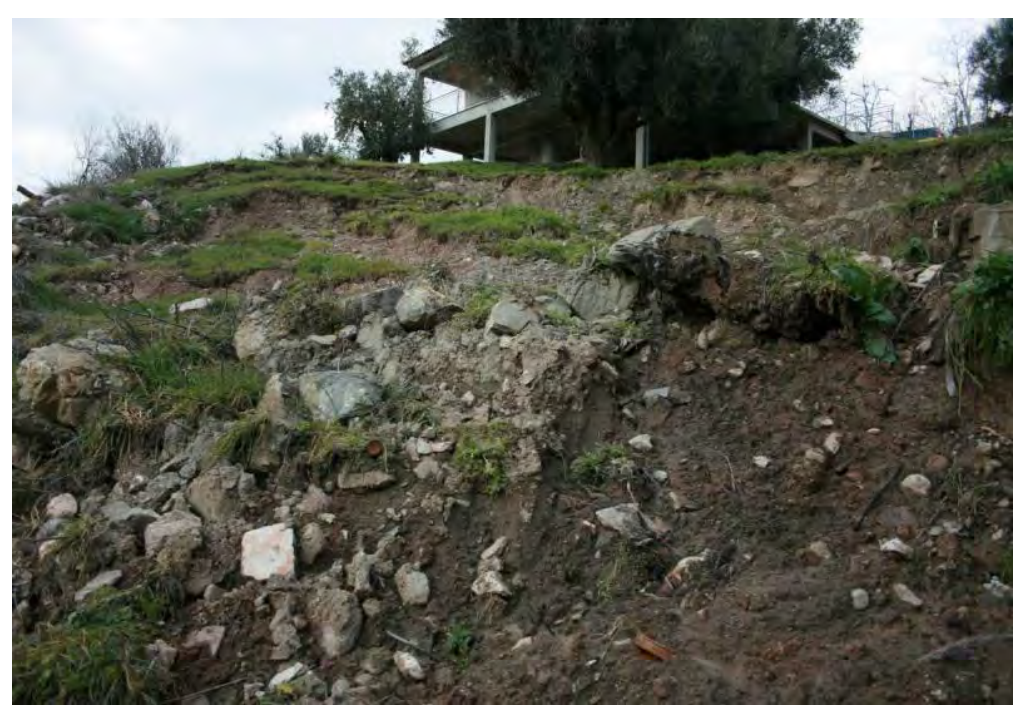

Figure 3. Photo of the landslide taken from the southeast. The head of the landslide is in front of two olive trees about two meters from the house basement.

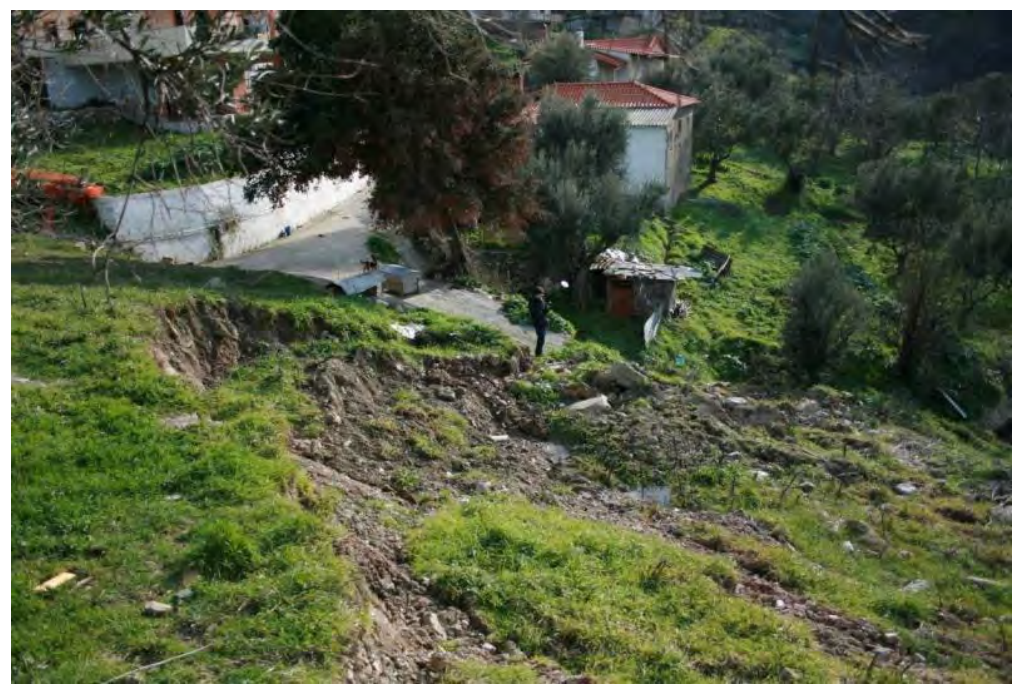

Figure 4 - Photo of the landslide taken from the northwest. Part of the small village road is collapsed.

Thirty ALOS PALSAR acquisitions within a period of three years were collected over the study area. As the landslide has been recorded on January 2009, the master and slave images of each interferometric pair had to be acquired before and after this date, respectively. Also, the interferometric pairs selected to have normal baseline component less than $1 \mathrm{Km}$ and time interval between 46 and 92 days ( $\mathrm{Ng}$ et al., 2008; Blanco et al., 2008). These restrictions were set on to avoid geometric and temporal decorrelation phenomena. So, two interferometric pairs were formed according to the selected criteria. The interferometric methodology was applied on each pair using the SARscape software.

\subsection{Results}

In Figures 5 and 6, are presented the geocoded differential interferograms and the magnifications of the area around the landslide, respectively for each interferometric pair. With a red circle is 
demonstrating the approximately site of the known landslide which has been measured by differential GPS.

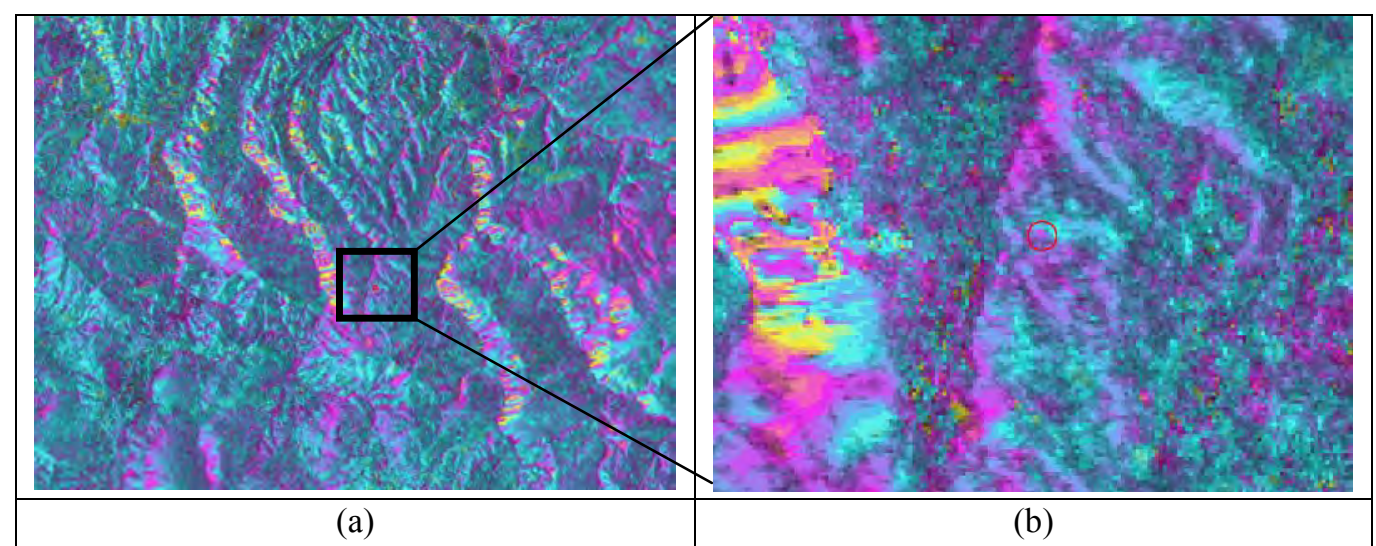

Figure 5 - (a) Geocoded Differential Interferogram from interferometric pair $20081110 \_20090210 / B n=824 m / \Delta t=92$ Days, (b) magnification of the area around the landslide.

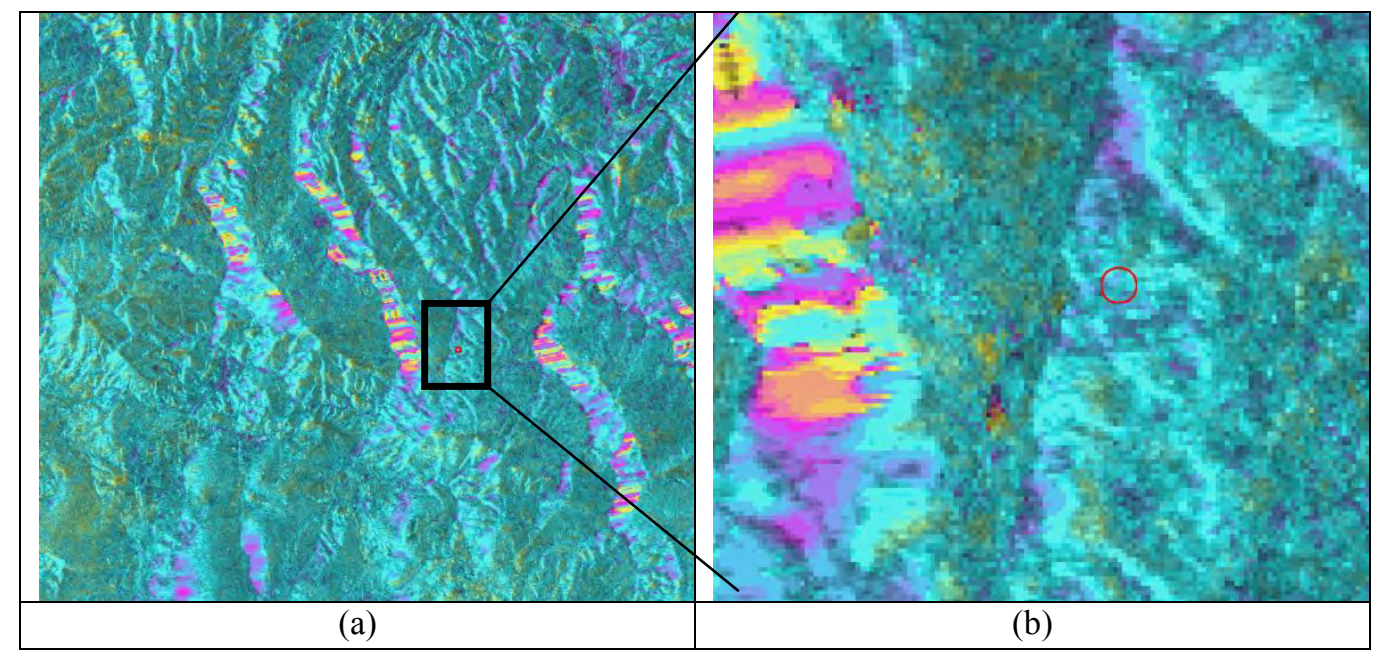

Figure 6 - (a) Geocoded Differential Interferogram from interferometric pair $20081226 \_20090210 / B n=671 \mathrm{~m} / \Delta \mathrm{t}=46$ Days, (b) magnification of the area around the landslide.

There are many studies where the conventional DInSAR had been used successfully to detect and map landslide by exploiting SAR acquisitions in L-Band (Kimura and Yamaguchi, 2000; Strozzi et al., 2003; Wegmüller, et al., 2008). However, in this study the identification of the known landslide in Sykies was not achieved. There are error sources which had been reported in the international literature and are the main limitations of conventional DInSAR in landslide monitoring applications (Colesanti and Wasowski, 2006; Cascini et al., 2009). The atmospheric phase delay variation, the geometric and temporal decorrelation, the external reference DEM, the aspect and inclination of slope are few reasons which affect the result of the conventional two pass DInSAR.

The atmospheric phase delay has considered as an error since the detection of a landslide is a non atmospheric application. The geometric and temporal decorrelation phenomena have been limited by the adoption of specific criteria on interferometric pair selection. The inaccuracies of the external DEM involved in the cancellation of the topography component from the signal interferences are limited since the used external DEM has high precision and accuracy. Finally, the used SAR 
images acquired over ascending orbits (line of sight pointing towards east) and the aspect of the study area is west/west-north. According to (Colesanti and Wasowski, 2006), the study area is affected by significant geometric distortions and especially by the distortion of foreshortening since the inclination of slope is about $22^{\circ}$ which is smaller than the off-nadir angle of ALOS sensor $\left(34,3^{\circ}\right)$. Nevertheless, in this study the main limitation on landslide identification is the very small area of the deformation. Specifically, the cell size of the geocoded interferograms had been selected to be $10 \mathrm{~m}$ (according to the best spatial resolution of ALOS Palsar data), so the area of the landslide mapped to three pixels approximately. The small area is linked directly to the spatial smoothing effect induced by interferogram filtering.

\section{ALOS Optical Data Processing}

Two ALOS Prism data sets with a spatial resolution of 2,5 meters and two ALOS AVNIR-2 sets with a spatial resolution of ten metes were used in this study. The first Prism and the first AVNIR2 images were acquired on 2008 before the landslide while the other data sets were acquired on 2009 after the catastrophic event. ALOS data was provided by the European Space Agency.

The 2008 Prism data set contains three scenes collected from the three radiometers. The 2009 Prism data set contains only the nadir and forward images. Thus four different stereo-pairs were used for the creation of four ALOS DSMs over the same area. Twenty-five ground control points and more than one hundred tie points were used. For all the stereo-pairs the same gcp's were used. Four DSMs with a pixel size of 7,5m were created. No further processing (editing) was done to the four DSMs. The DSM difference and elevation profiles were used for the landslide detection.

The two AVNIR-2 data sets were orthorectified using the DSM created from the ALOS Prism data and the same ground control points. Band 3 and band 4 were used for the calculation of the NDVI indices before and after the landslide. Because most of the landslides are usually bare of vegetation cover they present high reflectance. As a result big landslides can be detected from satellite data. As the vegetation cover usually changes due to the landslide there should be a quite big difference to the NDVI indices before and after the event.

The accuracy of DSMs created from ALOS stereopair was discussed in a previous paper (Nikolakopoulos et al., 2010). According to that study the accuracy of ALOS DSM is similar to the accuracy of the DSM of the Ministry of Agriculture (created from airphotos). In this study different elevation profiles were used in order to detect the landslide. The landslide head was used as one of the elevation profiles before and after the landslide. As we can observe in Figure 7 there is a difference to the elevation profile before and after the event. The landslide head line was between 496 and 494 meters before the landslide (figure 7 top) and its elevation decreased to 492 after the landslide (figure 7 bottom).

Two other elevation profiles along the landslide were created (Figure 2 brown color lines). As it can be observed in Figure 8 (top) the elevation before the landslide ranged between 495 and 498 meters. Along the same profile (Figure 8 bottom) the elevation decreased after the landslide and ranged between 492 and 496 meters.

The study of the NDVI images presented in Figure 9 has confirmed the existence of the landslide. The two images present quite big differences in the tonality. As the landslide has destroyed the vegetation cover the NDVI image of 2009 (Figure 9 right part) present higher values than the NDVI image of 2008 (Figure 9 left part). 

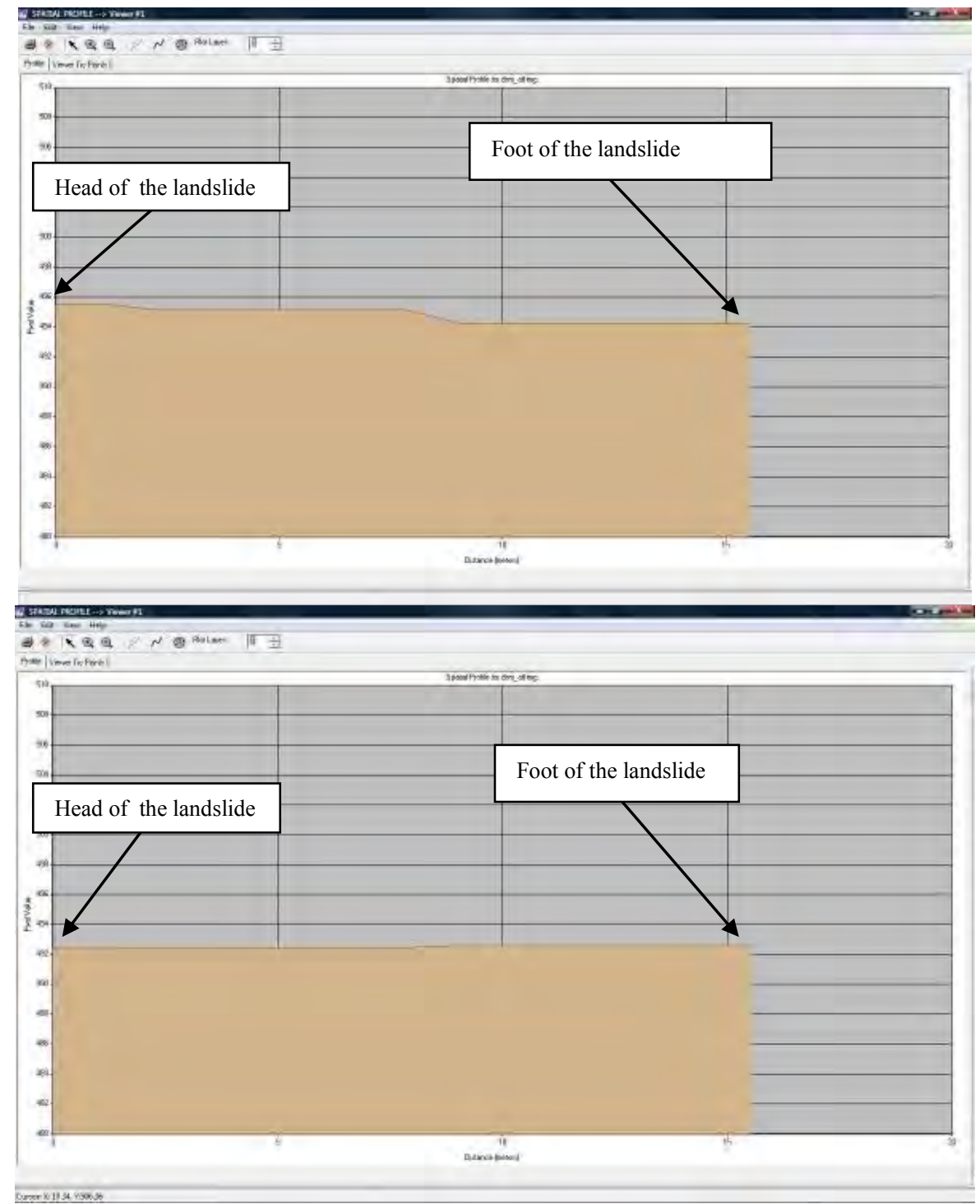

Figure 7. Elevation profiles along the landslide head. At the top the elevation profile from the 2008 stereopair. At the bottom the elevation profile of the 2009 stereopair. 

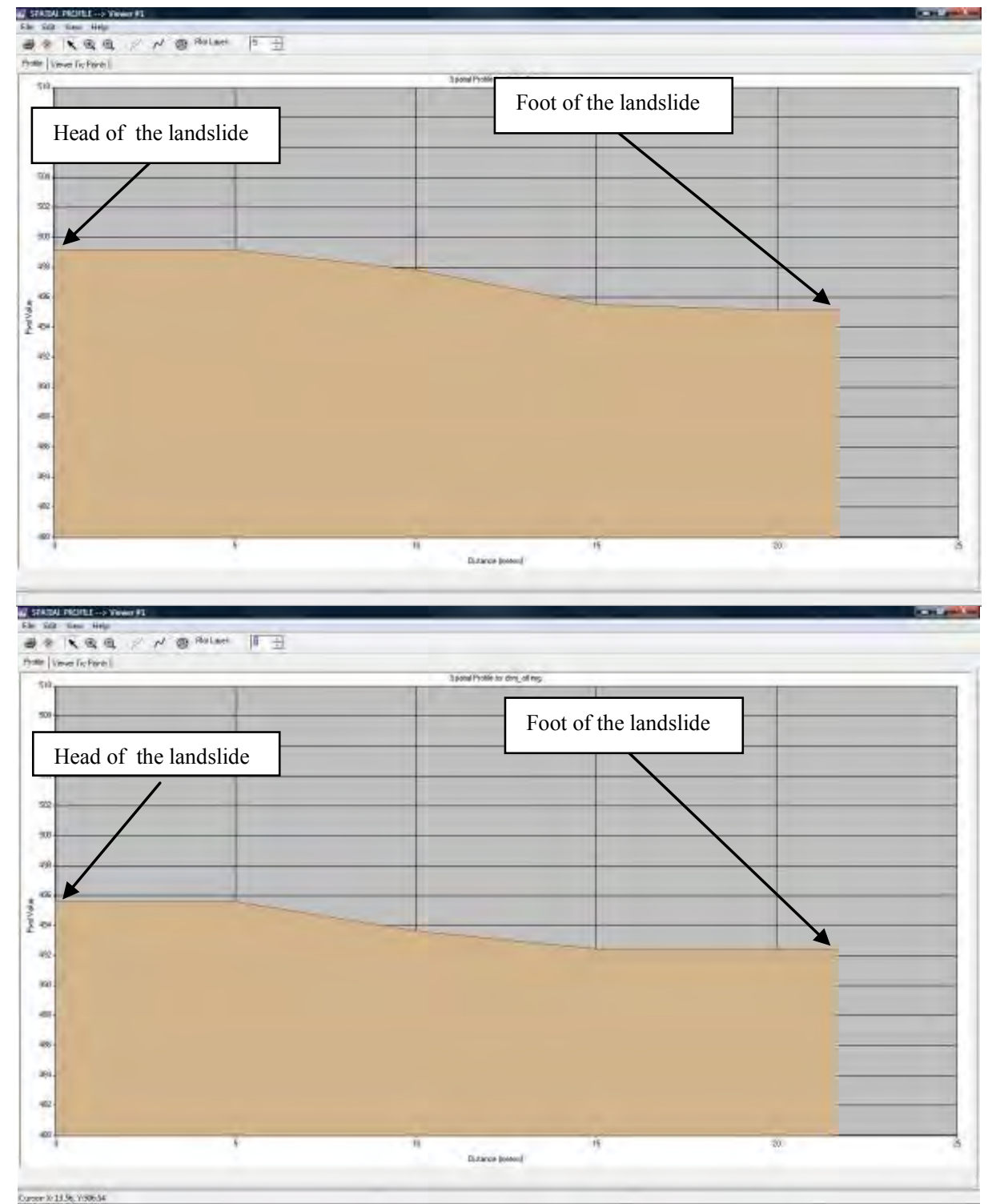

Figure 8. Elevation values along the profile no1. At the top the elevation profile from the 2008 stereopair. At the bottom the elevation profile of the 2009 stereopair. 

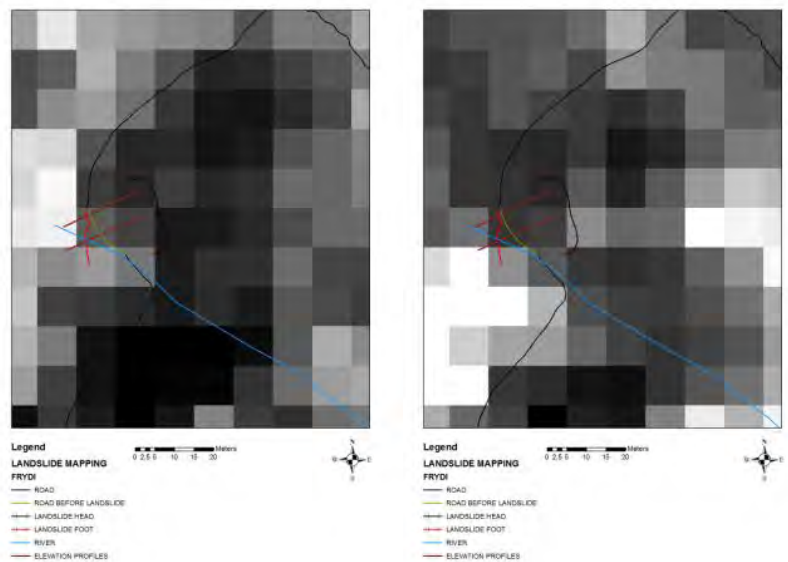

Figure 9. NDVI images produced from the ALOS VNIR-2 data before and after the landslide. At the left part the NDVI image of 2008 and at the right the respective image of 2009. The black dashed line represents the head of the landslide while the red one represents the foot of the landslide. The road network is presented with black color line.

\section{Conclusions}

In this paper the suitability of ALOS radar and optical data for landslide detection is discussed. A small landslide with a head of 27 meters length already mapped in situ with GPS was used for the testing. Thirty ALOS PALSAR acquisitions within a period of three years (before and after the event) were collected for the study area. Two ALOS Prism data sets with a spatial resolution of 2,5 meters and two ALOS AVNIR-2 sets with a spatial resolution of ten metes were used in this study. The first Prism and the first AVNIR-2 images were acquired on 2008 before the landslide while the other data sets were acquired on 2009 after the catastrophic event.

Standard two pass Differential SAR Interferometry was performed to detect the general ground deformation on the study area and specifically to identify and get information on the activity of the known landslide on Sykies. The detection of the landslide was not possible due to very small area of deformation. Specifically, the cell size of the geocoded interferograms had been selected to be $10 \mathrm{~m}$, so the area of the landslide mapped to three pixels approximately. The small area is linked directly to the spatial smoothing effect induced by interferogram filtering.

The DSM created from the ALOS PRISM data were proved suitable for the landslide detection. Different elevation profiles were examined and a decrease to the elevation values due the landslide has been marked.

\section{Acknowledgements}

The authors would like to acknowledge KTIMATOLOGIO S.A. for kindly providing the reference DEM for the study area. ALOS radar and optical data was provided by the European Space Agency under the PI project 6554.

\section{References}

Baum R.L., Messerich J. and Fleming R.W. 1998. Surface deformation as a guide to kinematics and three-dimensional shape of slow-moving, clay-rich landslides, Honolulu, Hawaii, Environmental and Engineering Geoscience, 4 (3), 283- 306.

Blanco P., Arbiol R. and Palà V. 2008. ALOS-PALSAR performances on a multiple sensor DInSAR scenario for deformation monitoring, Proceedings of the ALOS PI 2008 Symposium organized by ESA, Rhodes Island.

$\underline{\text { XLVII. No } 3-1498}$ 
Cascini L., Peduto D., Fornaro G., Lanari R., Zeni G. and Guzzetti F. 2009. Spaceborne Radar Interferometry for Landslide Monitoring, Proceedings of the ${ }^{1 s t}$ Italian Workshop on Landslides, (1), 138-144.

Chandler J.H. 2001. Terrain measurement using automated digital photogrammetry in: Griffiths, J.S. (Ed.), Land Surface Evaluation for Engineering Practice, Geological Society of London, vol. 18, 13- 18.

Colesanti C. and Wasowski J. 2006. Investigating landslides with space-borne Synthetic Aperture Radar (SAR) interferometry, Engineering Geology, 88, 173-199.

Jacobshagen V., Durr S., Kockel F., Kopp K.O. and Kowallczyck G. 1978. Structure and geodynamic evolution of the Aegean region, in: Alps, Appenines, Hellenides, H. Closs, D. Roeder \& K. Schmidt (Eds.), 537-564.

Kääb A. 2000. Photogrammetry for early recognition of high mountain hazards: new techniques and applications, Physics and Chemistry of the Earth, Part B 25 (9), 765- 770.

Kimura H. and Yamaguchi Y. 2000. Detection of Landslide Areas Using Satellite Radar Interferometry, Photogrammetric Engineering \& Remote Sensing, 66(3), 337-344.

Maas H.G. and Kersten T. 1997. Aerotriangulation and DEM/orthophoto generation from highresolution still-video imagery — on the potential of digital cameras onboard an aircraft, Photogrammetric Engineering and Remote Sensing, 63 (9), 1079- 1084.

Mantovani F., Soeters R. and Van Westen C.J. 1996. Remote sensing techniques for landslide studies and hazard zonation in Europe, Geomorphology, 15 (3-4), 213-225.

Massonet D., M. Rossi, C. Carmona, F. Adragna, G. Peltzer, K. Feigl and Rabaute T., 1993. The displacement field of the Landers earthquake mapped by radar interferometry, Nature, 364, 138-142.

Ng AH, Chang H., Ge L., Rizos C. and Omura M. 2008. Radar interferometry for ground subsidence monitoring using ALOS PALSAR data, in: Proceedings of the XXI congress, The International Society for Photogrammetry and Remote Sensing, Beijing.

Nikolakopoulos K.G., Vaiopoulos D.A., Skianis G., Sarantinos p. and Tsitsikas A, 2005. Combined use of Remote Sensing, GIS and GPS data for landslide mapping, IEEE IGARSS 7, 5196- 5199.

Nikolakopoulos K.G., Vaiopoulos A.D., and Tsombos P. 2010. DSM from ALOS data: the case of Andritsena, Greece, Proc. of SPIE, 7831, 78310K1-10.

Papanikolaou D. 1986. Geology of Greece, Eptalofos, Athens, 1-240.

Piper D.W.J. and Pe-Piper G. 1980. Was there an western (external) source of terrigenous sediment for the Pindos zone of the Peloponnese Greece? Neues Jahrbuch Geologie und Paleontologie, Monatsheft, 197-215.

Powers P.S., Chiarle M. and Savage W.Z. 1996. A digital photogrammetric method for measuring horizontal surficial movements on the Slumgullion earthflow, Hinsdale county Colorado, Computers and Geosciences, 22 (6), 651-663.

Strozzi T., Wegmüller U., Werner C., Wiesmann A. and Spreckels V., 2003. JERS SAR Interferometry for Land Subsidence Monitoring. IEEE Transactions on Geoscience and Remote Sensing, 41(7), 1702-1707.

Weber D. and Herrmann A. 2000. Contribution of digital photogrammetry in spatio-temporal knowledge of unstable slopes: the example of the Super-Saute landslide (Alpes-de-HauteProvence, France), Bulletin de la Societe Geologique de France, 171 (6), 637- 648.

Wegmüller U., Werner C., Strozzi T., Wiesmann A. and Raetzo H. 2008. Slope stability monitoring using space-borne repeat-pass SAR interferometry, Proc. of 13th FIG Symposium on Deformation Measurement and Analysis.

Yu G.H. and Ge L. 2010. Digital Elevation Model generation using ascending and descending multi-baseline ALOS/PALSAR radar images, In: FIG Congress 2010.

Zhou C., Ge L., Dongchen E. and Chang H. 2005. A case study of using external DEM in InSAR DEM generation, GeoSpatial Information Science, 8(1): 14-18. 